\title{
The safety of awake tracheal intubation in cervical spine injury
}

As a referral centre for cervical spine injuries, we have routinely performed awake tracheal intubation when intubation was indicated. A retrospective case control study was undertaken to review the frequency of neurological deterioration and aspiration associated with our approach. Neurological deterioration was assessed by a change in level of injury or neurological grade at admission and discharge. Four hundred and fifty-four patients with critical cervical spine and/or cord injuries were reviewed over an eight-year period. A case group of 165 patients underwent tracheal intubation awake within two months of injury. A control group of 289 remained unintubated during the same period. A comparison of spinal neurological status between admission and discharge revealed no statistically significant difference in neurological deterioration between the two groups. This occurred despite a greater injury severity score in the case group. No evidence of aspiration during intubation was documented. We conclude that awake tracheal intubation is a safe method of airway management in patients with cervical spine injuries.

En tant que centre de référence pour les traumatismes du rachis cervical, nous avons effectué de routine des intubations trachéales chez des patients éveillés lorsqu'indiquées. Une étude de dossier rétrospective a été menée afin de reviser la fréquence de détérioration neurologique et d'aspiration associée à notre approche. Une détérioration neurologique était évaluée par un changement dans le niveau du traumatisme ou dans le grade neurologique à l'admission et au départ. Quatre cent cinquantequatre patients avec un traumatisme critique de la moëlle épinière ou du rachis cervical ont été réévalués sur une période

\section{Key words}

COMPLICATIONS: intubation, trauma;

INTUBATION, TRACHEAL: complications, technique; SURGERY: orthopaedics, cervical spine.

From the Departments of Anaesthesia, Neurosurgery and Biostatistics, Sunnybrook Health Science Centre, University of Toronto.

Address correspondence to: Dr. J. Hugh Devitt, Department of Anaesthesia, Sunnybrook Health Science Centre, 2075 Bayview Avenue, Toronto, Ontario M4N 3M5.

Accepted for publication 2nd October, 1991.
Alfio Meschino MD FRCPC, J. Hugh Devitt MD MSc FRCPC, Jean-Paul Koch MD FRCPC, John Paul Szalai PhD, Michael L. Schwartz MD FRCSC de huit ans. Un group étude de 165 patients a subi une intubation trachéale lorsque éveillé en dedans de deux mois du traumatisme. Un groupe contrôle comprenait 289 patients n'ayant pas eu besoin d'intubation pendant la même période. Une comparaison de l'état neurologique rachidien entre les deux groupes, de l'admission au départ, n'a révélé aucune différence statistiquement significative dans la détérioration neurologique, et ce malgré un pointage de sévérité du traumatisme plus grand dans le groupe étude. Aucune évidence d'aspiration n'a été documentée durant les intubations. Nous en concluons que l'intubation trachéale chez un patient éveillé est une méthode sécuritaire pour contrôler les voies aériennes des patients avec des traumatismes du rachis cervical.

Patients with cervical spine injuries remain a challenge in anaesthesia. Sunnybrook Health Science Centre is a tertiary referral point for patients with multiple trauma and spinal injuries. Between April 1989 and the end of March $1990,15 \%$ of patients admitted to our institution with major or multiple blunt injuries had a critical cervical spine injury. Airway management of these patients remains controversial. Prospective randomized studies looking at the method of choice for intubating trauma patients with cervical injuries are either logistically or ethically impossible to complete, as patients are usually unable to give consent due to the nature of their injuries. Anecdotal case reports or series describing management of patients with cervical fractures continue to be published. ${ }^{1,2}$ With few exceptions, our approach towards tracheal intubation in this population over the last decade has been to employ awake intubation. A review of charts of patients with cervical spine injury presenting in an eight-year period was undertaken to determine the safety of our approach.

\section{Methods}

The charts of all patients with cervical spine injuries (with or without spinal cord injury) admitted between 1980 and 1987 were reviewed. All patients reviewed had a critical cervical spine injury and all received rigid neck immobilization, usually with halo traction or vest. Some patients required open reduction and fixation of cervical vertebrae at a later date. The diagnosis of cervical spine injury was 
TABLE I Sunnybrook cord injury scale

\begin{tabular}{cl}
\hline Grade & Description \\
\hline 1 & Complete motor loss; complete sensory loss \\
2 & Complete motor loss; incomplete sensory loss \\
3 & Incomplete motor useless; complete sensory loss \\
4 & Incomplete motor useless; incomplete sensory loss \\
5 & Incomplete motor useless; normal sensory \\
6 & Incomplete motor useful; complete sensory loss \\
7 & Incomplete motor useful; incomplete sensory loss \\
8 & Incomplete motor useful; normal sensory \\
9 & Normal motor; incomplete sensory loss \\
10 & Normal motor; normal sensory \\
\hline
\end{tabular}

made on admission by clinical examination, standard radiographs (odontoid, anteroposterior and lateral cervical spine views), and computed tomographic scanning where required.

Patients were excluded from further study for the following reasons:

(i) intubation under general anaesthesia with or without neuromuscular junction blockade (mainly at the referring hospital);

(ii) associated severe head injury precluding adequate clinical neurological examination and assessment of spinal function;

(iii) urgent surgical airway (tracheostomy or cricothyrotomy);

(iv) cervical spine injury of indeterminate age.

Data collected from each patient included age, injury severity score (ISS), level of cervical spine fracture, and neurological grade of injury. The neurological status was determined by the level of neurological lesion and neurological grade at admission and discharge. A standardized cord injury scale was used to grade the neurological injury. ${ }^{3}$ This scale subcategorizes patients in regard to motor and sensory function within any given level of spinal cord lesion. Table I details the grading system. Other information collected included mode of trauma, method of intubation, indications for intubation, and any evidence of pulmonary aspiration of gastric contents during intubation.

Patients were divided into two groups depending on the need for intubation during their hospitalization. The control group comprised those patients who were not intubated. The case group consisted of those undergoing tracheal intubation within a two-month period of admission. Although variable among patients, two months was chosen as an upper limit of the healing of a spinal fracture to stability.

\section{Statistical methods}

Cases and controls were compared on the proportion of individuals with worsening neurological status through the
TABLE II Mechanism of injury

\begin{tabular}{lr}
\hline & $n$ \\
\hline 1 Motor vehicle accident & 264 \\
2 Fall & 94 \\
3 Diving accident & 60 \\
4 Sports and recreational & 27 \\
5 Industrial accident & 7 \\
6 Airplane crash & 1 \\
7 Gunshot wound & 1 \\
Total & 454 \\
\hline
\end{tabular}

TABLE III Technique of intubation

\begin{tabular}{lll}
\hline & $n$ & $\%$ \\
\hline Fibreoptic bronchoscope, oral or nasal & 76 & 46 \\
Blind nasal tracheal & 53 & 32 \\
Direct laryngoscopy, oral & 36 & 22 \\
\hline
\end{tabular}

normal curve approximation of the differences between independent proportions. ${ }^{4}$ Where the difference between proportions was found to be not significant, the extent of clinical equivalence of the two proportions through the confidence limits method was determined. ${ }^{5,6}$ Cases and controls were also compared on their mean age and mean ISS through one-way analysis of variance. A $P$ value of $<0.05$ was used in rejecting the null hypotheses.

\section{Results}

Five hundred and forty-seven patients were admitted between 1980-1987 with cervical spine fractures with or without cord lesions. The records of 13 patients could not be found. Eighty patients were excluded from further study for the criteria mentioned above. Of the remaining 454 patients, 289 did not require tracheal intubation (controls), while 165 required tracheal intubation (cases). Mechanism of injury in these patients is listed in Table II. Within the control group, 277 patients had a halo vest and/or halo traction applied. The remaining 12 were managed with four-post or Philadelphia collars. In the case group, the tracheas of 42 patients (25\%) were intubated before any form of rigid immobilization could be applied. In 64 patients (39\%) intubation was performed under emergency conditions. In 137 patients (83\%), intubation was assisted by a regional block or local anaesthesia of the larynx. The method of intubation was unrestricted and is presented in Table III. Indications for intubation were not restricted and included protection of airway, respiratory failure, tracheobronchial toilet, and provision of general anaesthesia. Indications are presented in Table IV. All intubations were performed with the patient awake without the aid of general anaesthesia or muscle relaxants.

Seven of the 289 controls (2.4\%) and four of the 165 
TABLE IV Indications for intubation

\begin{tabular}{lrr}
\hline & $n$ & $\%$ \\
\hline Surgery & 103 & 62.4 \\
Respiratory & 44 & 26.7 \\
Airway protection & 13 & 7.9 \\
Tracheo-bronchial toilet & 5 & 3.0 \\
\hline
\end{tabular}

TABLE V Age and severity of injury (yr, mean \pm SD)

\begin{tabular}{lll}
\hline & Age & ISS \\
\hline Controls & $37.9 \pm 20.4$ & $15.3 \pm 6.7$ \\
Cases & $35.4 \pm 18.6$ & $23.8 \pm 9.3$ \\
\hline
\end{tabular}

cases $(2.4 \%)$ demonstrated neurological worsening between admission and discharge as assessed by changing neurological level or grade. Of the four patients with neurological deterioration undergoing tracheal intubation, two deteriorated before intubation and two afterwards. Both patients who deteriorated after tracheal intubation did so several hours later and had a normal post-intubation neurological examination. The observed proportions of neurological worsening were 0.024 for both cases and controls, which were not statistically different. The $95 \%$ confidence limits of the differences between the proportion for controls and cases was \pm 0.029 .

The ISS was higher for cases than controls $(P<0.001)$ (Table V), but there was no difference in mean ages. There was no documented evidence of pulmonary aspiration of gastric contents in the intubated patients as a complication of intubation.

\section{Discussion}

It has been the policy at our institution to perform tracheal intubation awake in those patients with cervical spine and/or cord injuries who require it. The frequency of neurological deterioration was the same whether or not tracheal intubation was performed suggesting clinical equivalence even though patients requiring intubation were more severely injured. On this basis, one might have expected a higher proportion of patients in the case group displaying neurological worsening than in the control group. No evidence of aspiration during tracheal intubation was recorded.

The report by Doolan and O'Brien reviews anatomy and pathophysiology of cervical spine fractures and concludes that tracheal intubation is safe with the aid of general anaesthesia in experienced hands. ${ }^{1}$ Suderman et al. reported on 62 patients with cervical spine and/or cord injuries, of which 43 underwent tracheal intubation with the aid of general anaesthesia and the remaining 19 had tracheal intubation performed awake. They found no neurological deterioration in either group. ${ }^{2}$ The problems with this study include lack of randomization, no comparison of severity of injury between the group intubated under general anaesthesia and those intubated awake, exclusion from study of patients with complete cord injury so that they would not have detected a rising level of complete cord injury, and the method of determining neurológical function and deterioration was not described. Our main concern is the lack of a large enough sample to generate a reasonable base rate of secondary or worsening neurological deficits which we and others have shown to be approximately $1.5-2.5 \% .^{7}$ In other words, sample size of the study group was not large enough to provide the study with adequate statistical power.

Post-hoc power calculations suggest that to detect differences between percentages of $3.5 \%$ and $0 \%$ with 0.80 statistical power the study sample size would have to be 420 patients. $^{8}$

Three concerns frequently arise and perhaps discourage the use of awake intubation. Awake intubation may increase intracranial pressure (ICP) in patients with concomitant head injury. To our knowledge, this has not been substantiated in acutely traumatized patients. In this group of patients, hypoxia and hypercapnia are more likely to cause a critical rise in ICP than are transient changes associated with airway manipulation. ${ }^{9}$ Barbiturates effectively blunt the ICP response to tracheal intubation but do not improve outcome from traumatic head injury. ${ }^{10}$ Furthermore, barbiturates can be dangerous in the hypovolaemic and haemodynamically unstable patient with a potentially difficult airway.

Secondly, we have not noticed a single documented report of pulmonary aspiration in our series of patients. Where there was vomiting in a few instances, patients were able to protect their airways by coughing as they were not rendered unconscious. Ovassapian, in a prospective study, revealed no aspiration in the presence of a full stomach when topical anaesthesia was used during awake intubation. ${ }^{11}$

Thirdly, the perceived difficulty in learning and mastering awake intubation techniques appears to prevent a widespread acceptance of these techniques. The majority of awake intubations in our series were performed by anaesthesia residents in training. The residents were not taught the importance of any one technique of awake intubation. Whatever the method used, the emphasis is on the awake patient for he/she may be the ultimate spinal cord monitor. ${ }^{12}$

Our study suffers from several design problems. This was a non-randomized, nonblinded chart review with the potential for reviewer bias. While a prospective, randomized study is preferable, ethically and medico-legally in many countries, it is difficult to randomize trauma patients 
during the acute resuscitation whether it is for method of intubation or for any other form of therapy. However, our study assessed a large number of patients over a long period of time. In our institution we are involved in all phases of trauma resuscitation, not only when the patient presents to the operating room.

Cervical spine fractures can be missed by history and physical examination alone. ${ }^{13}$ Furthermore, critical cervical injuries may not be identified by standard crosstable lateral and A-P views of the cervical spine. ${ }^{14,15}$ Even more alarming, the incidence of secondary deficits in patients not initially recognized as having suffered a spinal injury is $10.5 \%$ compared with $1.4 \%$ in those correctly diagnosed at the time of presentation. ${ }^{7}$ It is logical to consider every trauma victim as having a cervical spine fracture until proved otherwise. In cadavers, oro-tracheal intubation, as well as other non-surgical airway management techniques, such as head extension and chin lift, may aggravate cervical spine fractures by causing displacement at the fracture site. ${ }^{16}$ This also occurs with other neck manoeuvres including cricoid pressure. ${ }^{17}$ It is our impression that patients may provide some protection to their own spinal cords during tracheal intubation by splinting the injury site with muscle spasm and pain, although we are unaware of any corroborating evidence. Furthermore, patients can act as the ultimate spinal cord function monitor during the procedure itself.

In conclusion, awake tracheal intubation of patients with cervical spine injuries in our institution is safe. We feel that until a study is conducted that demonstrates safety when utilizing general anaesthesia to perform tracheal intubation in cervical spine-injured patients we will continue with awake tracheal intubation.

\section{Acknowledgement}

The authors wish to acknowledge the assistance of Nancy Huntley with the preparation of the manuscript.

\section{References}

1 Doolan $L A, O^{\prime} B$ rien $F J$. Safe intubation in cervical spine injury. Anaesth Intensive Care 1985; 13: 319-24.

2 Suderman VS, Crosby ET. Elective intubation in the unstable cervical spine patient. Can J Anaesth 1990; 37: S122.

3 Tator CH, Rowed DW, Schwartz ML. Sunnybrook cord injury scales for assessing neurological injury and neurological recovery. In: Tator CH (Ed.). Seminars in Neurological Surgery; Early Management of Acute Spinal Cord Injury. New York: Raven Press, 1982: 7-24.

4 Fleiss $J$. Statistical methods for rates and proportions. 2nd ed. New York: John Wiley and Sons, 1981: 39.

5 Dunnell $C W$, Gent $M$. Significance testing to establish equivalence between treatments with special reference to data in the form of 2 by 2 tables. Biometrics 1977: 33: 593-602.

6 Detsky AS, Sackett AL. When is a "negative" clinical trial big enough? How many patients you need depends on what you found. Arch Intern Med 1985; 145: 709-12.

7 Reid DC, Henderson R, Saboe L, Miller JDR. Etiology and clinical course of missed spine fractures. J Trauma 1987; 27: 980-6.

8 Donner A. Approaches to sample size estimation in the design of clinical triais; a review. Statistics in Medicine 1984; 3: 199-214.

9 Frost EAM. Effects of positive end-expiratory pressure on intracranial pressure and compliance in brain injured patients. J Neurosurg 1977; 47: 195-200.

10 Schwartz $M L$, Tator $C H$, Rowed $D W$ et al. The University of Toronto head injury treatment study: a prospective randomized comparison of Pentobarbital and Mannitol. Can J Neurolog Sci 1984; 2: 434-40.

11 Ovassapian A, Krejcie T, Yelich S, Dykes M. Awake fiber-optic intubation in the patient at high risk of aspiration. Br J Anaesth 1989; 62: 13-6.

12 Zigler J, Rockowitz N, Capen D, Nelson R, Waters $R$. Posterior cervical fusion with local anaesthesia: the awake patient as the ultimate spinal cord monitor. Spine 1987; 12: 206-8.

13 Jacobs $L M$, Schwartz $R$. Prospective analysis of acute cervical spine injury: a methodology to predict injury. Ann Emerg Med 1986; 15: 44-9.

14 Shaffer MA, Doris PE. Limitation of the cross table lateral view in detecting cervical spine injurjes: a retrospective analysis. Ann Emerg Med 1981; 10: 508-13.

15 Streitwieser DR, Knopp $R$, Wales $L R$ et al. Accuracy of standard radiographic views in detecting cervical spine fractures. Ann Emerg Med 1983; 12: 538-42.

16 Aprahamian C, Thompson BM, Finger WA, Darin JC. Experimental cervical spine injury model: evaluation of airway management and splinting techniques. Ann Emerg Med 1984; 13: 584-7.

17 Sellick BA. Cricoid pressure to control regurgitation of stomach contents during induction of anaesthesia. Lancet 1961; 2: 404-6. 